\title{
Corrigendum: About Glassy Amorphous Metal Injection
}

\author{
${ }^{1}$ Raffaella Aversa, ${ }^{2}$ Relly Victoria Petrescu, ${ }^{1}$ Antonio Apicella, ${ }^{3}$ Samuel Kozaitis, ${ }^{4}$ Taher Abu-Lebdeh, ${ }^{5}$ Bilal \\ Akash and ${ }^{2}$ Florian Ion Tiberiu Petrescu
}

\author{
${ }^{1}$ Advanced Materials Lab, Second University of Naples, Naples, Italy \\ ${ }^{2}$ IFToMM, ARoTMM, Bucharest Polytechnic University, Bucharest, Romania \\ ${ }^{3}$ Florida Institute of Technology, USA \\ ${ }^{4}$ North Carolina A and T State University, USA \\ ${ }^{5}$ Dean of School of Graduate Studies and Research, American University of Ras Al Khaimah, UAE
}

Correction to: International Journal of Structural Glass and Advanced Materials Research

http://doi.org/10.3844/sgamrsp.2018.96.106, published online 22 January 2018; updated 29 April 2019

The original version of this Article contained Mr. MirMilad Mirsayar as a CoAuthor. Mr. Mirsayar has not contributed to the preparation and publication of this manuscript.

These errors have now been corrected in the HTML and PDF versions of the Article. http://doi.org/10.3844/sgamrsp.2018.96.106. 